\title{
30
}

\section{Apologies, Liability and Civil Society: Where to from Here?}

\author{
Prue Vines
}

\section{Introduction}

In this chapter I argue that there is a major need for obligations law to expand its consideration of what amounts to compensation, in order for true corrective justice to operate. For my purposes I will mainly consider the law of negligence for personal injury. There is good reason to think that an excessively legalistic approach to compensation has been problematic, even merely in terms of the monetary amounts that plaintiffs receive, for example, for personal injury. It may be time to abandon the idea of restitutio in integrum (putting the injured person in the position they would have been in if the accident had not happened) in respect of damages, so rarely does this actually appear to happen, ${ }^{2}$ and replace it with a combination of monetary and other forms of compensation including apologies. In this chapter I consider why an apology might be seen as part of corrective justice, and argue that any reduction or lack of litigation caused by apologies might occur because one of the aims of tort law, that

1 Professor, Faculty of Law, University of New South Wales: p.vines@unsw.edu.au.

2 Prue Vines and Matthew Butt, 'Running Out of Compensation Money: Whipping Away the Social Security Blanket?' (2013) 7 Court of Conscience 17; Genevieve Grant et al, 'When Lump Sums Run Out: Disputes at the Borderlines of Tort Law, Injury Compensation and Social Security' in Kit Barker et al (eds), Private Law in the 21st Century (Hart Publishing, 2016). 
of corrective justice, has been met by the apology itself. This requires us to consider the nature of loss as it is felt by the person and as it is recognised by the legal system in tort.

In this chapter I define an apology as a communication between parties expressing regret for harm that has been done by one party to the other, acknowledging fault, and accompanied either by compensation or a promise to ensure the wrong will not happen again. ${ }^{3}$ I argue that in the law of torts there is a place for both the spontaneous and the coerced apology.

\section{The Needs of Civil Society Go Beyond the Rule of Law}

As lawyers we are constantly aware of the rule of law and its importance for civil society. However, how this is considered depends partly on the 'thickness' of the rule of law concept. Where a 'thin' rule of law concept is used, referring to bare legal rules, there may nevertheless be a real lack in the civil society which is facilitated by that rule of law. By this I mean that when bare legal rules are used, a formalistic and less substantive idea of the rule of law is in play. A 'thicker'4 idea of the rule of law, I argue, sees it embedded in the culture of the society in which it operates, and therefore partakes of a richer sense of what the rules mean. This means, for example, that the purpose of the rule is more likely to be applied than the literal rule because the law can take account of the context within which it operates. Another way of considering this is through an expressive theory of law, ${ }^{5}$ that the rules of law operate in a way which goes beyond the minimal verbal content, and in their expression may touch and affect social norms.

3 See, inter alia, Prue Vines, 'Apologising for Personal Injury in Law: Failing to Take Account of Lessons from Psychology in Blameworthiness and Propensity to Sue' (2014) 16 Psychiatry, Psychology and Law 42.

4 Drawing on Clifford Geertz, 'Thick Description: Toward an Interpretive theory of Culture' in Clifford Geertz (ed), The Interpretation of Cultures (Basic Books, 1973) who saw 'thick' description in ethnography as a way of including the context and often the perspective of the observer.

5 Cass Sunstein, 'On the Expressive Function of Law' (1996) 144(5) University of Pennsylvania Law Review 2021; Elisabeth S Anderson and Richard H Pildes, 'Expressive Theories of Law: A General Restatement' (2000) 5 University of Pennsylvania Law Review 1503. 
As our understanding of both moral reasoning and rationality, along with neuropsychology, develops, it becomes clearer that the emotional life of the human being cannot be severed from reason ${ }^{6}$ and has a large part to play in the development of moral and other values. Emotional responses such as disgust, fear, guilt and anger often underlie our 'rational' discourse and help to shape the values articulated in the rational discourse. Law then should reflect an understanding of the emotional life of the people it affects.

The apology is best thought of as a communication of emotion and values: the emotion is remorse or 'sorriness' and the values are those which have been damaged by the wrong which is being apologised for. In this way an apology is an exemplar of the notion that reason and emotion can combine to produce and/or reflect values. Where a wrong has occurred, the best apology occurs where the wrongdoer spontaneously and promptly apologises, acknowledging the wrong and seeking either to prevent it happening again and/or providing compensation. In some cases this reduces the desire to sue or allows for early settlement. ${ }^{7}$ But this is not the only possible use of an apology. The fact that the apology recognises values means that in some circumstances even a coerced apology can have value for the victim. This is because where the court or society requires an apology from the wrongdoer the victim feels vindicated. In such a case what matters for the victim is their standing in the community; the fact that the wrongdoer has not (sincerely) acknowledged their wrongfulness does not matter, because the broader community has done so.

\section{The Treatment of Apologies in Civil Liability}

One recent shift in the legal landscape has been an increasing interest in apologies in transitional justice, and within the legal system. Within the legal system this has been embodied in the move to protect apologies from automatically creating liability by legislation in many countries since $1996 .{ }^{8}$ This has been done for two main reasons: to reduce litigation, and

6 For example, Martha Nussbaum, Upheavals of Thought: The Intelligence of Emotions (Cambridge University Press, 2001); Dylan Evans and Pierre Cruse (eds), Emotion, Evolution and Rationality (Oxford University Press, 2004).

7 Prue Vines, 'Apologies and Civil Liability in the UK: A View from Elsewhere' (2008) 12(2) Edinburgh Law Review 200-30.

8 All Australian jurisdictions, most US States, England and Wales, most Canadian jurisdictions and Scotland all now have various forms of this legislation. See, for example, Civil Liability Act 2002 (NSW) ss 68-69. The legislation varies considerably in its scope and its definition of apology, but mostly prevents the apology (however defined) from being admissible as evidence of liability or from creating liability. 
to ensure that the normal processes of civil society (apologising when one has done something wrong) are not disrupted by an excessively legalistic (one might argue 'thin' or 'non-expressive') view of law. Apologies, although often seen as merely offering sympathy or acknowledgement of fault, may also have a remedial aspect.

Liability in negligence generally results in damages. Damages operate as compensation, as a marker of wrongdoing and as acknowledgment that redress is needed. Apologies do some of the same work. Damages also address needs and many people regard this as the most significant aspect of damages. If damages are only about need, then a no-fault scheme is the best way to deal with loss. ${ }^{9}$

The idea that damages put the person back into the position they were in before the wrong happened ${ }^{10}$ has become almost laughable. However, damages are often seen also as the central vehicle of corrective justice in that they operate to redress the balance between the parties by correcting the loss suffered by one party at the expense of the other who caused it. Apologies can be part of this corrective justice process if one considers damages as practical reparation and apology as emotional reparation for the emotional and moral pain suffered by the victim. Some have called this 'symbolic' reparation, but this is only symbolic if one does not regard humiliation or emotional pain as real.

\section{Corrective Justice: Balancing Symbolic, Emotional and Monetary Needs}

\section{A. Corrective justice and apologies}

Aristotelian notions of corrective justice focus on the dyad where one party hurts the other, and then the balance between the parties must be corrected or equalised. Michael S Moore's definition is as follows:

9 See, for example, Harold Luntz, 'Reform of the Law of Negligence: Wrong Questions Wrong Answers' (2002) 8(2) UNSWLJ Forum: Reform of the Law of Negligence: Balancing Costs and Community Expectations 18.

10 See above $n 3$. 
a corrective justice view of tort law asserts that we all have primary moral duties not to hurt others; when we culpably violate such primary moral duties, we then have a secondary moral duty to correct the injustice we have caused. Tort liability rules are no more than the enforcement of these antecedently existing moral duties of corrective justice. ${ }^{11}$

This firmly focuses on the relationship between law and morality. Moore's definition is 'thin' in that it does not take much account of the relationship between law, morality and emotion. I would argue that part of the necessary correction of the injustice includes recognition of the emotional need for vindication ${ }^{12}$ which I see as part of corrective justice. Other corrective justice theorists have also generally used a 'thin' view of law. For example, Weinrib, ${ }^{13}$ referring to the fact that Aristotle talked about the correlative relationship between the parties in terms of equalising gain and loss, dismisses the fact that in negligence there is no gain apparent. When we look at what is happening, the injured person has a loss, and in paying compensation the wrongdoer in turn suffers loss. Weinrib argues that this is merely a problem of terminology and the loss or gain is only 'normative'. But to say that the correlativity is 'only' normative misses a great deal of the moral richness of tort law. It may be that there is a gain when someone negligently inflicts injury on another: that gain is a gain in power, ${ }^{14}$ which we mostly pay little attention to, but nevertheless it is a gain which needs to be countered by a loss of power. It can be argued that an apology, which is necessarily humbling, reduces that gain and redresses the wrong and that this is one of its reparative functions.

Apologies focus on the moral wrongfulness of the action taken by the perpetrator. This seems to differ from negligence law which only makes a person liable for a wrong when the wrong has caused a harm (outcome responsibility). ${ }^{15}$ However, psychological studies have shown that the more serious the consequences are, the more likely there is to

11 'Causation and Responsibility' (1999) 16(2) Social Philosophy and Policy 1 at 4.

12 Jason Varuhas, 'The Concept of Vindication in the Law of Torts' (2014) 34 (2) Oxford Journal of Legal Studies 253.

13 'The Gains and Losses of Corrective Justice' (1994) 44 Duke Law Journal 277.

14 Aquinas suggests that 'a person striking or killing has more of what is evaluated as good, insofar, that is, as he fulfils his will, and so is seen to receive a sort of gain' in James Gordley, 'The Aristotelian Tradition' in David Owen (ed), Philosophical Foundations of Tort Law (Oxford University Press, 1995), 138.

15 Steven Perry has argued in 'The Moral Basis of Tort Law' (1992) 77 Iowa Law Review 449, 497 that the individualised sense of fault which focuses Weinrib's corrective justice theory should be modified by outcome responsibility to better reflect the law of negligence. 
be attribution of moral responsibility to the person who caused them. ${ }^{16}$ That is, outcome responsibility does seem psychologically to increase people's perception of moral fault. The assignment of responsibility is a very complex part of human behaviour ${ }^{17}$ to which the law should respond. The psychological needs of individuals and communities, and the needs of moral communities, are part of the social context in which tort law operates and it is important to have some kind of link between the legal and the moral/psychological universes. Apologies, both spontaneous and as remedies, can do some of this work. ${ }^{18}$

Corrective justice's goal of equality between the parties and co-relativity between the wrong and the righting of the wrong requires proportionality between the wrong, the harm and the compensation. Compensation for negligence may not do this, despite the assumption of corrective justice that the loss is the same as the wrongfulness. In a negligence action the wrong may be small, but the loss very large. The distinction between loss and wrong and the possible disproportion between the wrong and what is seen as redressing the wrong causes major problems in social perceptions of the legitimacy of negligence. The fact that apologies focus on moral wrong, and that they have a healing and reparative function of their own, may be used to redress partially this disproportion in some cases. It is important to be able to avoid a punitive response. ${ }^{19}$ In cases where apologies have been ordered, judges have emphasised that such apologies are ordered for redress not punishment. ${ }^{20}$

16 Kelly Shaver, 'Redress and Conscientiousness in the Attribution of Responsibility for Accidents' (1970) 6 Journal of Experimental Social Psychology 100; Elaine Walster, 'Assignment of Responsibility for Accidents' (1966) 3 Journal of Personality and Social Psychology 1973; David Kanouse, 'Language, Labelling and Attribution' in Edward E Jones et al (eds), Attribution: Perceiving the Causes of Behaviour (General Learning Press, 1972).

17 The psychological studies of attribution show a number of things of interest to negligence theory, including first that the assignment of moral responsibility is very complex and may be altered by very subtle semantic shifts, second that levels of generality of explanation beget explanations at similar levels of generality, and third that there is indeed a naïve sense of moral responsibility. See, inter alia, Sally Lloyd-Bostock, 'Attributions of Cause and Responsibility as Social Phenomena' in Joseph Jaspars, Frank Fincham and Miles Hewstone (eds), Attribution Theory and Research (Academic Press, 1983).

18 Prue Vines, 'The Power of Apology: Mercy, Forgiveness or Corrective Justice in the Civil Liability Arena' (2007) 1 Journal of Public Space 1-51, epress.lib.uts.edu.au/ojs/index.php/publicspace/home; Robyn Carroll, 'Beyond Compensation: Apology as a Private Law Remedy' in Jeff Berryman and Rick Bigwood (eds), The Law of Remedies: New Directions in the Common Law (Irwin Law, 2010) 323.

19 Carroll, above n 18.

20 Carroll (above n 18) refers to De Simone v Bevacqua (1994) 7 VAR 246 (a harassment case); Falun Dafa Association of Victoria Inc v Melbourne City Council [2004] VCAT 625; Ma Bik Yung v Ko Chuen [2002] HKLRD 1. 


\section{B. The conception of loss, apologies and compensation}

The recognition of loss for the purposes of negligence has developed over time from the purely physical (e.g. personal injury and property damage), ${ }^{21}$ to economic loss and mental harm. The latter is still restricted in Australia (but not everywhere else) to psychiatrically recognisable harm and distinguished firmly from 'distress or sorrow'. ${ }^{22}$ However, in other domains loss includes injury to personhood, reputational torts being the obvious example. At present when a tort arises, damages are awarded for the recognised losses, but this fails to account for the fact that when a person is harmed a loss may occur which is felt as an injury to personhood, caused by the wrong as well as the harm. This loss, the emotional reaction to the wrong, can be characterised as a normative loss separate from the physical realm. It may well be an experiential loss for the person, but it is also an objective injury to personhood or human dignity which it is important for the legal system to consider in terms of expressive theory or a 'thicker' view of law. It is important to recognise this sort of loss because, if fault is not acknowledged, some litigants will remain unsatisfied, even if they do obtain some form of compensation. It is this type of loss for which an apology may compensate. A damages award coupled with an order to apologise is more likely to vindicate both the physical and emotional loss caused by the harm and give satisfying redress.

\section{Conclusion}

The distinction and/or the disproportion between wrongfulness and loss in negligence law can be addressed to some extent by apologies. When spontaneous and immediate, apologies may reduce the desire to sue or make it easier to settle early. As remedies, coercive apologies may offer better vindication than damages alone. The law of obligations has taken insufficient care to maintain civil society by failing to adequately recognise the emotional content of the disputes which the law seeks to deal with.

21 For example, in Donoghue v Stevenson [1932] AC 562, Mrs Donoghue sued for personal injury (gastro-enteritis) and nervous shock (psychiatric harm). It is doubtful whether she could have sued for nervous shock then had she not had the physical injury as well. Until Hedley Byrne \& Co Ltd $v$ Heller \& Partners Ltd [1964] AC 465 it was assumed that pure economic loss was the domain of contract and that one could not sue for it in negligence, and so on.

22 Mount Isa Mines Ltd v Pusey (1970) 125 CLR 383 per Windeyer J at 403 and much repeated; Civil Liability Act 2002 (NSW) s 30 and its equivalents. 
The treatment of apologies in civil liability is a case in point. The usual advice not to apologise ignores the needs of civil society and its members for responses other than monetary damages. Reform of the law should move towards the significance of humans' emotional as well as legal life, maintaining the balance of symbolic, emotional and monetary needs in the response to civil wrongs. It is time to order apologies along with damages in such cases. Apologies and damages in various combinations may address both the aims of corrective justice and compensation better and more comprehensively than the declaration of liability in a judgment with damages awarded, as a form of recognition of the fact that the nature of loss is broader than the legal system normally allows. Considering apologies in this way, rather than ignoring them, will allow us more completely to meet the claims of corrective justice; and offers a better chance of the tort process offering real healing than it does at present. 
This text is taken from New Directions for Law in Australia: Essays in Contemporary Law Reform, edited by Ron Levy, Molly O’Brien, Simon Rice, Pauline Ridge and Margaret Thornton, published 2017 by ANU Press, The Australian National University, Canberra, Australia. 